\title{
Employee's Participation in Decision Making and Manager's Encouragement of Creativity: The Mediating Role of Climate for Creativity and Change
}

\author{
Ali Zubair1, Mohsin Bashir ${ }^{1}$, Muhammad Abrar ${ }^{2}$, Sajjad Ahmad Baig², Shaher Yar Hassan1 \\ ${ }^{1}$ Department of Business Administration, Government College University, Faisalabad, Pakistan \\ ${ }^{2}$ Department of Business Administration, National Textile University, Faisalabad, Pakistan \\ Email: mohsinhust@gmail.com
}

Received 13 March 2015; accepted 19 May 2015; published 22 May 2015

Copyright (C) 2015 by authors and Scientific Research Publishing Inc.

This work is licensed under the Creative Commons Attribution International License (CC BY).

http://creativecommons.org/licenses/by/4.0/

\section{(c) (i) Open Access}

\section{Abstract}

This paper examined the relationships among employee's participation in decision making (PDM), manager's encouragement of creativity (MEOC) and employee's creativity (CTY) and the role of climate for creativity and change (CLT) as a possible mediator among the relationships. Multisource data was collected from 206 employees and their managers. The results indicated that employee's participation in decision making and manager's encouragement of creativity were positively related with employee's creativity. Support was also found for the role of climate for creativity and change as a partial mediator. Findings suggested that employee's creativity was positively related with employee's participation in decision making and manager's encouragement of creativity through climate for creativity and change.

\section{Keywords}

Participation in Decision Making, Manager's Encouragement of Creativity, Employee's Creativity, Climate for Creativity and Change

\section{Introduction}

Currently organizations are working in very competitive and uncertain dynamic environment, which requires organizations to be flexible, to acquire and adapt new knowledge, new technologies and new processes to intro-

\footnotetext{
${ }^{*}$ Corresponding author.
} 
duce new products, services, cut costs, act faster than competitors and remain competitive. Creativity has been argued to be necessary for organizations to gain competitive advantage [1]. When employees act creatively they generate unique ideas on which organization can capitalize by developing and implementing the suggested new product, process or procedure.

Considering the importance of creativity in organizations Today, this study investigated whether employee's participation in decision making and manager's encouragement of creativity is related to employee's creative behavior and climate for creativity and change mediates the relationship?

Historically, researchers believed that the creativity was dependent on characteristics of individuals and focused their work on explaining them (cognitive ability, education, experience, habits, etc.) [2]. The research focused on differences between individuals led to a few crucial conclusions about the backgrounds, working habits and personalities of creative people. Contemporary view of creativity says that every individual possesses the ability to be somewhat creative and work environment influences creativity. Researchers began to study organizations environments in search of climates that promote or impede creativity [3]-[6]. While there is fair amount of knowledge that personality characteristics are related to employee's creativity and contextual factors either enhance or decrease creativity, it is important to identify leader's role in encouraging employee's creativity. Managers or supervisors are in direct contact with employees and their role in motivating employees is very critical (Mohammed, 2007). Many researchers have written about the direct relationship of leader's behavior with employee's creativity [7], a few have written about indirect relationship more importantly the indirect relationship of leaders behavior, creativity and climate [8]. Supervisor is an immediate force which effects employee's perception of the work environment [7]. Managerial encouragement is frequently discussed variable that have been argued to effect creativity. Participation can also result from managerial encouragement. Participation in decision making affects job satisfaction, employee's performance, organization's productivity, employee's motivation and organization commitment [9]-[13]. All of these variables have significant impact on creativity [12] [14] [15]. As involving employees positively affect all these variables, we argue that involving employees in decision making will also increase employee's creativity. Also Muindi [12] articulated participation's effect on creativity. In this paper managerial encouragement and participation are both examined to find objective evidence of their effect on creativity.

\section{Literature Review}

\subsection{Employee's Participation in Decision Making}

Participative decision making is a managerial strategy which has been argued to affect the performance, organization commitment, turnover, motivation and satisfaction of the employees, organization productivity [12] [13] [16]-[20]. Organization performance, organization commitment, employee's turnover and satisfaction have significant relationship with creativity [15] [21]-[23]. Participation improves organization performance, employee's satisfaction, motivation and decreases the turnover rate, that's why involving employees in decision making will increase employee's creativity. Introducing participation in work group is argued to affect innovation and creativity [24] [25].

Organizational commitment has positive influence on employee's creativity [21] [15]. Employees who participate in decision making have positive attitude toward the organization and are committed to their jobs and organization [9]. A significant and positive impact of job satisfaction exists on employee's creativity [23] and significant strong positive relation exist between participation is decision making and job satisfaction [4]. There is a significant relationship between employee involvement in decision making and firm's performance [14] [20]. Participation in decision making results in satisfaction of employees and increase in productivity and profit [14]. Since PDM is positively related with organization commitment, job satisfaction, motivation and performance it will increase creativity as well. When employees provide input in decision making, changes are implemented effectively and creativity, which is an important benefit of participative decision making [12]. Employees are central to idea generation, without them there will be no ideas to implement (innovation) so they should be encouraged and involved in decision making. Participation can increase social interactions, discussions and support innovation; hence it is argued that employee's participation in decision making will have positive relationship with their creativity.

Employees are central to the generation of useful unique ideas but this does not mean other organizational 
factors that influences creativity should be ignored. These factors (e.g., leadership, freedom, resources, time availability, organization encouragement, rewards, and performance evaluation) reside in the work environment or social environment. Both componential theory of creativity and interactionist theory include social environment as a factor affecting creativity [4] [26]. Creative work environment is characterized by organization encouragement, group support, and autonomy, challenging work, supervisory encouragement and sufficient resources [5]. Communication and involvement was found to be particularly significant in creating a climate of creativity [27]. Freedom in work and risk taking has been encouraged to foster creativity [5] [28] [29] and freedom can be linked with risk-taking as taking risk is dependent on having freedom in how to do the work. Freedom and risk-taking are important as they enable employees to explore for creative solutions and try new ways of doing work. One effect of implementing participative decision making can be the freedom of employees or teams to decide how to carry out its task. Idea flow, participative decision making and management are important parts of organization encouragement of creativity [5]. Support was found as only predictor of innovation in groups or teams by Anderson and West [30] and work group support may be increased by implementing participative decision making. Availability of resources also has been described to have determining effect on creativity [5] [6] [31]. By implementing participative decision making employees can have more control over the allocation and utilization of resources. Managers who have positive attitude toward change create a climate that is conducive of continues adoption of new ideas [6] by involving employee's in decisions and managers can nourish such climate. By involving employees in decisions resource allocation, freedom, rewards system, supervisor subordinate communication, goals, group composition can be effected which are the factors of work environment so it is proposed that involvement of employee's in decision making will effect work environment.

Many mediating variables are suggested that could explain the link of PDM to creativity. Improved work environment was also suggested as a mediator that might explain PDM link to creativity [32]. Isaken et al. [32] argued that climate was an intervening variable between individual and organization performance. Creative climate was found to mediate the relation of HPWS (involvement was one of the practices) and performance (innovation was one of the performance measures) [27]. Freedom in work, efficient utilization of employee's knowledge and diversity, increased social support and organization encouragement are mediating factors between participation and creative behavior [33]. Studies identified factors which effect creativity. These factors include supervisory encouragement, organizational encouragement, group support, resource availability, freedom, challenging work, productivity, group diversity, communication, rewards system, evaluation system, rigid rules [1] [3] [5] [6] [29]. Since climate for creativity is conducive to creativity characterized by elements that support and enhance creativity, it is hypothesized that the effect of employee's participation in decision making on creativity will be mediated by climate for creativity.

\subsection{Manager's Encouragement of Creativity}

Managers can encourage employees to be creative by articulating reason for creative job outcomes, stating what organization values, and putting attention to the effectiveness of engaging in creative processes is most likely to result in creative outcomes. Encouragement of creativity is the most discussed dimension in the literature [5]. Leader's encouragement of creativity is defined as the extent of a leader's emphasis on being creative and on actively engaging in processes that may lead to creative outcomes. Such emphasis will facilitate employee's effort toward creative response [34]. Managers should focus on encouraging and supporting employee's as creativity is more likely to occur if leaders are supportive [8]. Managers are in direct contact with employees and their role in motivating employees is crucial (Mohammed, 2007). Creativity involves risk-taking and motivation of employees toward creativity warrants that they feel encouraged to take risks and break out of routine work [8]. Encouraging employees to be creative or motivating them to engage in creative thinking will effect work environment in a way that employees will see organization as supportive of creativity and will engage in such behavior. Team leader (supervisor, manager) is an immediate force that can make an impression on team's experience of the work environment [7] which will in turn affect their creative behavior. Employees are creative when they have creativity relevant personal characteristics, challenging jobs, and are supported by supervisors [1].

Leaders can affect employee's creativity through their behaviors that might encourage or discourage employee's to come up with new ideas by taking risk. Leaders can also affect creativity indirectly [35]. Perceived leader support is positively and significantly related with subordinate's creativity [7]. Management style and leadership was identified as a factor influencing organizations capability to manage innovation [36]. Zhang and 
Bartrol [34] found that leader's encouragement of creativity moderated the relationship between psychological empowerment and creative process engagement which influenced employee's creativity. A study by Ahmadi and Emamipour [37] examined relationship of organization climate and employee's creativity, and found a significant and positive relationship between manager's behavior and employee's creativity. Supervisory encouragement is one of the factors which effect creativity and innovativeness [6]. Employees are a source of ideas so they should be encouraged to ensure a healthy supply of ideas to input into innovative process [36]. If employees are encouraged to be creative they will surely be motivated to engage in thinking at things from different perspective, gathering information and which will result in creative alternatives.

Creativity is effected by team composition (e.g. diversity), team characteristics (e.g., cohesiveness, team size), team processes (e.g., social information processes, problem solving strategies), and contextual influences [4]. Supervisory encouragement is one of the contextual influences that effect creativity [29]. In componential theory of creativity, Amabile articulated three individual level components (domain relevant skills, task motivation and creativity relevant processes) and one component independent of individual the work environment will effect creativity [26] [38] and managers can influence these components of creativity [29].

Componential theory of creativity articulated by Amabile [26] states creativity is influenced by individual components and work environment. Work environment includes factors which serve as stimulants or obstacles of intrinsic motivation. Supervisory encouragement is quoted as stimulant of intrinsic motivation which is a core element of creativity [26] [38]. Intrinsic motivation will determine what an individual is willing to do to achieve an objective [5]. Open supervisory interactions and perceived supervisory support affect creativity and under these conditions employees will less likely experience fear of negative criticism that can undermine intrinsic motivation necessary for creativity [5]. Employees produce creative work when employees have creativity related characteristics, complex challenging jobs and supervised in supportive and noncontrolling way [1]. Work environment is made up of organizational motivation or encouragement, management practices and resources [5] and all of these components are deemed necessary for innovation to foster. Managerial practices identified by Amabile are challenge, freedom, resources, work-group features, supervisory encouragement, and organizational support which enhance or kill creativity [29]. Leadership has not been studied as an important influence on creativity, despite its effect on work environment and the effect of work environment on creativity [7]. Organization managers can influence novel productivity and the climate for creativity and innovation. Climate for creativity was proposed as intervening variable between individual creativity and team creativity; result supported the preposition [39]. Leaders can influence novel output, organization climate for creativity and creativity [32]. Leaders can effect employee's creativity through their behaviors that might encourage or discourage employees to come up with new ideas by taking risk and leaders can also affect creativity indirectly by influencing work environment [35]. According to componential theory social environment has factors which enhance or impede creativity. Challenging work, freedom in carrying decisions, collaborative, diverse and idea focused teams, recognition of creative work, supervisory encouragement of idea generation and top management supporting creativity will enhance creativity while harshly criticizing new ideas, problem of status que, low risk attitude of top management will block creativity [38]. Leaders play important role in eliminating factors that decrease creativity and maintaining aspects which enhances creativity [35]. Leaders need to play active role in fostering, supporting and encouraging creativity. Hence, leader's role is to make sure that work environment and human resource practices (e.g., resources, rewards and evaluations) are such that creative outcomes can occur [40]. Rewards, evaluation, resources and support [5] are closely tied with creative behavior of employees therefore leaders should link them so creativity is perceived as important. For example if employees are evaluated as creative, but they are never rewarded or provided access to required resources, they might receive mixed signals and discontinue to behave in creative way. Therefore managers need to plan which behaviors or outcomes they want and based on that they need to support, reward and evaluate their employee's.

Ekvall and Ryhammar [41] by examining the creative climate found that climate had significant effect on organizational outcomes and organization resources, leadership style and structure had significant impact on both organization climate and organizational outcomes. Gelade and Ivery [42] found significant correlation among HRM practices, work climate and organization performance. Further they found that effect of HRM practices was mediated by work climate on organization performance. As leaders can influence factors of work environment which either increase or decrease creativity, and work environment can effect creativity, it is hypothesized that work environment will mediate between managers encouragement of creativity and employee's creativity. 


\section{Materials and Methods}

\subsection{Conceptual Framework (Figure 1)}

PDM and MEOC are the independent variables. Employee Creativity is the dependent variable and Climate for Creativity and Change is the mediator variable. The model examines the direct effect (c1 and c2) and indirect effect (b) of PDM and MEOC on employee's creativity via climate for creativity and change. Path a1 will show the effect of PDM on CLT and path b will show the effect of CLT on CTY. By multiplying path a1 and b we will have the indirect effect of PDM on CTY. Likewise a2 will show the effect of MEOC on CLT and by multiplying a2 and b we will have the indirect effect of MEOC on CTY. We will use process procedure developed by Hayes (2013) to calculate direct and indirect effects of independent variables and check the significance of the effects.

\subsection{Measures}

\subsubsection{Participation in Decision Making}

Employee's participation in decision making was measured using Ruh's [11] five-item measure. Employees were asked to indicate the extent to which they were involved in decision making. Responses were recorded on 5 point likert scale ranging from 1 ("far too little") to 5 ("far too much"). Sample item include "In general, how much say or influence do you have on what goes on in your work group?”

\subsubsection{Manager's Encouragement of Creativity}

Manager's encouragement was measured with Zhang and Bartol's [34] six-item measure. Employees rated their manager's encouragement by indicating the extant on a 5 point likert scale ranging from 1 ("strongly disagree") to 5 ("strongly agree"). Sample items include "My manager allows employees to try to solve the same problems in different ways".

\subsubsection{Climate for Creativity and Change}

Climate for creativity and change was measured using situational outlook questionnaire developed by Isaken and Lauer [43] to access the climate consisting of 9 items, measuring all nine dimensions of creative environment. Responses were taken from employees on a 5 point likert scale ranging from 1 ("strongly disagree") to 5 ("strongly agree"). Sample items include "People on this team trusted each other, were open and honest and count on each other for personal support”.

\subsubsection{Employee's Creativity}

Managers assessed the creativity of employee's, which was defined in the instruction as the generation of novel and useful ideas by their teams. Zhou and George's [44] scale was used, for each item, managers were asked to indicate the extent to which employees were creative on a 5-point scale ranging from 1 (strongly disagree) to 5 (strongly agree). Sample item includes "This employee is not afraid to take risks".

\subsection{Sample}

A cross sectional research methodology was adopted. Data was collected from different organizations and groups of people at one particular time to examine the effect of employee's participation in decision making and

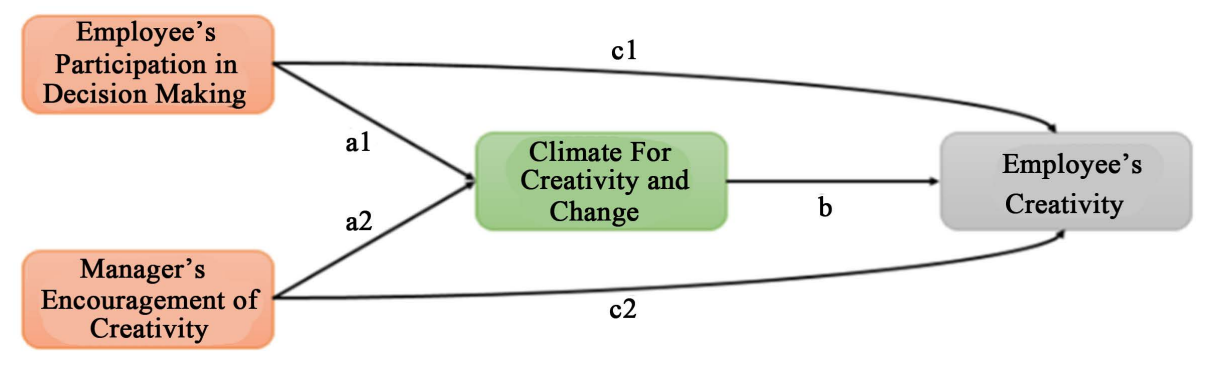

Figure 1. Conceptual framework. 
manager's encouragement of creativity on climate for creativity and change and employee's creativity. Data was collected from individual working in telecommunication, textile and FMCG sector using questionnaires. Top management of the organization was contacted to introduce the study and ask for permission. After getting approval to conduct study, collection of data was commenced from the teams and their managers working in a particular department (e.g. marketing, research and development) or organization. Data was collected from 206 employees and 34 managers personally during work hours by administering questionnaires. Mean age of the aanagers was 34.68 years old and mean age of the employees was 29.15 years old. Age range for the managers was 27 to 45 years old and for the employees was 22 to 47 years old. 132 (64\%) employees had Master's degree, 68 (33\%) had Bachelor's degree and 6 (3\%) had engineering degree. 180 (87.4\%) employees were males and 26 (12.6\%) were females. 110 (53.4\%) employees had more than one years' experience, 79 (38.3 \%) had more than five years' experience, 8 (3.9) had more than ten years' experience, 4 (1.9 \%) had more than fifteen years' experience and 5 (2.4\%) had more than 20 years' experience. Data was analyzed using SPSS employing process procedure (a regression based approach) by Hayes (2013).

\subsection{Hypotheses}

The aim of current study is to test the following hypotheses.

H1. Employee's participation in decision making and manager's encouragement of creativity are positive predictors of employee's creativity.

H2. Employee's creativity is related with employee's participation in decision making and manager's encouragement of creativity via climate for creativity and change.

\subsection{Reliability of the Measurement Tools}

Cronbach Alpha (reliability coefficient) was calculated for internal consistency of each variable measure. Cronbach alpha for all the measures was greater than 0.70 which was considered good. The results are as shown in Table 1.

\subsection{Statistical Treatment}

In this study process procedure developed by Hayes [45] is used to conduct mediation analysis which calculates regression models as suggested by Baron and Kenny [22], in addition to that it calculates normal theory test (known as sobel test) and Kappa-squared (k2) test [46] of indirect effect significance with bias corrected bootstrap confidence intervals in SPSS v.21. Andy Field [47] also endorsed the use of bootstrapped confidence intervals over sobel and preferred the use of effect size $\mathrm{k} 2$ with confidence intervals. Process procedure [48] can be used to estimate the mediation model that includes multiple independent variables each linked to same mediator. Process cannot include all independent variable in the model simultaneously. To estimate mediation model with two independent variables, I ran process procedure two times to get the indirect effect confidence intervals and Normal theory tests of indirect effect for confirming mediation. All other coefficients (e.g. path a, path b and path c) would be the same in both outputs. One independent variable was taken as independent variable and other as covariate in process procedure. Covariate will be treated exactly as independent variable with paths to dependent and mediator variables. Table 4 shows the results when PDM is included as independent variable and MEOC as covariate. Table 5 shows the results when MEOC is included as independent variable and PDM as covariate. Coefficients from both of these tables then are used to explain indirect of both independent variables (PDM and MEOC).

Table 1. Cronbach alpha reliability test.

\begin{tabular}{ccc}
\hline Variable Measure & No. of Items & Cronbach Alpha \\
\hline PDM & 5 & 0.74 \\
MEOC & 6 & 0.73 \\
CLT & 9 & 0.75 \\
CTY & 13 & 0.79 \\
\hline
\end{tabular}




\section{Results}

To test that multicollinearity does not exist between predictor variables, variance inflation factor (VIF) and tolerance test was employed, taking into account VIF does not exceed value 10 and the value of Tolerance Test is greater than 0.10 [48]. The "tolerance" is an indication of the percent of variance in the predictor that cannot be accounted for by the other predictors, hence very small values indicate that a predictor is useless. The VIF, which stands for variance inflation factor, is $1 /$ tolerance and as a rule of thumb, a variable whose VIF value is greater than 10 suggests high multicollinearity. The results of tolerance and VIF tests are shown in Table 2 below.

Table 2 shows that VIF values for all the variables are less than 10 ranging from 1.33 to 1.75 and the values of tolerance test are above 0.10 which means more than $10 \%$ variance in predictor variable is not predicted by other variables. Tolerance test value of PDM is 0.75 which means $75 \%$ variance in PDM is not predicted by other predictors (MEOC and CLT) in the model. Similarly 61\% variance in MEOC and 57\% variance in CLT is not predicted by other predictors in the model. Results suggest multi co linearity does not exist between predictor variables.

Correlation analysis revealed positive correlation between study variables. Predictor variables (PDM, MEOC) positively correlated with suggested mediator (CLT) and mediator variable correlated positively with outcome variable (CTY). It has been found that participation in decision making correlates positively with manager's encouragement of creativity $(r=0.41)$ and climate for creativity and change $(r=0.47)$. Manager's encouragement of creativity correlates positively with climate for creativity and change $(r=0.61)$ and employee's creativity $(r=$ $0.52)$. Climate for creativity and change correlates positively with employee's creativity $(r=0.58)$. Table 3 below shows mean, standard deviation and correlation of study variables.

CLT has the highest mean value (3.88) followed by CTY (3.76), MEOC (3.74) and lastly PDM (3.67). Mean value of CLT (3.88) tells us that employees perceive their work environment as supportive of creativity and change, if this value was $3(3=$ neutral $)$ or less than $3(2=$ disagree and $1=$ strongly disagree $)$ then it would mean employees perceived their work environment not supporting of creativity and change. Mean value of CTY (3.76) tells us that supervisors perceive their subordinates creative. Mean value of MEOC (3.74) tells us that managers or supervisors encourage their subordinates to engage in creative behavior. At last mean value of PDM (3.67) tells us that employees are involved in decision making, too.

From mean and standard deviation value, it is clear that majority of employees and supervisors rated items of measurement tool ranging from neutral to strongly agree, which means we can hope to find results as hypothesized.

\section{Results of Hypothesis Tests}

H1: Employee's participation in decision making and manager's encouragement of creativity are positive predictors of employee's creativity.

Table 2. Tests of Tolerance and VIF.

\begin{tabular}{ccc}
\hline Predictor Variables & Tolerance & VIF \\
\hline PDM & 0.75 & 1.33 \\
MEOC & 0.61 & 1.64 \\
CLT & 0.57 & 1.75 \\
\hline
\end{tabular}

Table 3. Correlations, means and standard deviations of study variables.

\begin{tabular}{cccccc}
\hline & Mean & SD & PDM & MEOC & CLT \\
PDM & 3.67 & 0.52 & - & & \\
MEOC & 3.74 & 0.47 & 0.4 & $.61^{* *}$ & - \\
CLT & 3.88 & 0.40 & $0.47^{* *}$ & $.52^{* *}$ & $.58^{* *}$ \\
CTY & 3.76 & 0.42 & $0.49^{* *}$ & - \\
\hline
\end{tabular}

Note: $\mathrm{n}=206,{ }^{* *} \mathrm{p}<0.001$. 
Part D of Table 4 and Table 5 shows the regression model of the effect of independent variables PDM and MEOC on employee's creativity (CTY) and model summary. PDM $(\beta=0.27, \mathrm{p}<0.001$, CI $[0.18,0.37])$ and MEOC $(\beta=0.34, \mathrm{p}<0.001$, CI $[0.23,0.45])$ both significantly and positively predicts CTY. Both independent variables are explaining $36 \%\left(\mathrm{R}^{2}=0.36\right)$ variation in CTY. This means if employees participate in decision making and their manager encourages them to behave creatively their creativity will increase. The effect of PDM on CTY is path c1 and effect of MEOC on CTY is path c2 in Figure 2. Hypothesis 1 is accepted.

H2: Employee's creativity is related with employee's participation in decision making and manager's encouragement of creativity via climate for creativity and change.

From results shown in Table 4, Part E, indirect effect of employee's participation in decision making on employees creativity via climate for creativity and change was significant, $\beta=0.07$, CI $[0.03,0.13]$ after controlling for the effect of MEOC on the model and Normal theory tests for indirect effect was also significant $(\beta=0.07, \mathrm{p}$ $<0.01)$. In addition to that results indicated that $\operatorname{PDM}(\beta=0.20, \mathrm{p}<0.01$, CI $[0.10,0.30])$ was still significantly predicting outcome variable CTY after including CLT in the model thus results suggest partial mediation by PDM. For accepting Hypothesis 2 we need evidence that CLT is also a significant mediator between MEOC and CTY. To prove this we look at results from Table 5 Part E, when MOEC was included as independent variable and PDM was entered as covariate. Indirect effect of manager's encouragement of creativity on employees creativity via climate for creativity and change was also significant, $\beta=0.15$, CI $[0.09,0.23]$ and Normal theory tests for indirect effect was also significant $(\beta=.15, \mathrm{p}<.001)$. In addition to that results indicated that MEOC $(\beta=$ 0.19 , $\mathrm{p}<0.001$, CI $[0.07,0.31]$ ) was still significant after including CLT in the model thus suggesting partial mediation by CLT between MEOC and CTY. Climate for creativity and change is also a partial mediator between manager's encouragement of creativity and employee's creativity. It was found that both independent variables (PDM and MEOC) had indirect effect on dependent variable (CTY) through mediator variable (CLT), so hypothesis 2 is accepted. Climate for creativity and change partially mediated the effect of employee's participation in decision making and manager's encouragement of creativity on employee's creativity. SPSS version of Process output from Table 4 and Table 5 are further discussed in detail below.

Part A in Table 4 and Table 5 displays the variables in the mediation model where $\mathrm{X}$ is independent variable, $\mathrm{Y}$ is dependent variable and $\mathrm{M}$ is the mediator variable. Part A also shows statistically controlled variable and sample size which is 206 subjects. In Table 4 MEOC is controlled and indirect effect of PDM on CTY through CLT is measured. In Table 5 PDM is controlled and indirect effect of MEOC on CTY through CLT is measured.

Part B in both tables (Table 4 and Table 5) shows the impact of independent variables PDM and MEOC on mediator variable CLT. Impact of PDM on CLT $(\beta=0.21$, p $<0.001$, CI $[0.12,0.29])$ and impact of MEOC on $\operatorname{CLT}(\beta=0.42, \mathrm{p}<0.001$, CI $[0.32,0.52])$ is significant and positive and they represent Path a1 and Path a2 in Figure 2 respectively. Since zero is not in the range of CI, the effect of PDM and MEOC on CLT is significantly different from zero. PDM and MEOC together explains $43 \%\left(\mathrm{R}^{2}=0.43\right)$ variation in CLT. This implies that if employees are allowed to participate in decision making and their managers encourage them to be creative, a positive climate for creativity and change will foster.

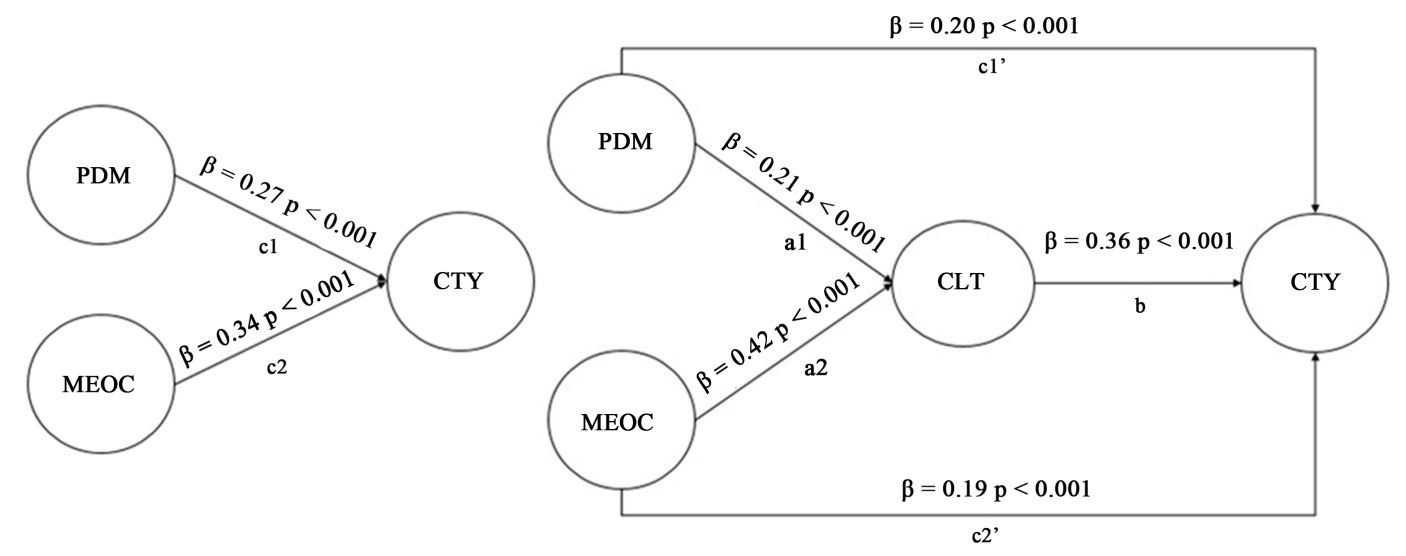

Figure 2. Total, direct \& indirect effect of PDM \& MEOC on CTY. 
Table 4. PROCESS procedure for SPSS release 2.12.1.

\section{Effect of PDM on CTY via CLT}

Part A. Variables Model = 4; Y = CTY; X = PDM; M = CLT; Statistical Controls: CONTROL= MEOC; Sample size: 206

Part B. Outcome: CLT Model Summary

$\mathrm{R}$

0.66

R-sq
0.43

MSE

0.09

F

76.37

Df1

2.0000

Model

$\begin{array}{ccc} & \text { Coeff } & \text { SE } \\ \text { Constant } & 1.56 & 0.1 \\ \text { PDM } & 0.21 & 0.0 \\ \text { MEOC } & 0.42 & 0.05\end{array}$

$\mathrm{R}$

0.65

$\begin{array}{ll}\mathrm{R} & \mathrm{R}-\mathrm{sq} \\ 65 & 0.43\end{array}$

SE

$\mathrm{t}$

$\mathrm{p}$

LLCI

ULCI

0.19

8.23

0.0000

1.19

1.94

0.04

4.63

0.0000

0.12

0.29

0.05

8.57

0.0000

0.32

0.52

Part C. Outcome: CTY Model Summary

MSE

F

Df1

50.24

3.0000

Df2

P

Model

Constant

CLT

PDM

MEOC

Coeff

SE

0.92

0.36

0.20

0.19

0.23

t

p

LLCI

3.94

0.0001

0.46

4.78

0.0000

0.21

4.06

0.0001

0.10

0.0024

0.07

202.0000

0.0000

3.08

TOTAL EFFECT MODEL

Part D. Outcome: CTY Model Summary
Df1

2.0000

Df2

203.0000

$\mathrm{p}$

0.0000

$\begin{array}{cc}\text { R } & \text { R-sq } \\ 0.60 & 0.36\end{array}$

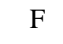

57.71

0.11

Model

Coeff

Constant

PDM

MEOC
1.48

0.27

0.34

$\mathrm{t}$

6.95

5.53

6.14

$\mathrm{p}$
0.0000
0.0000
0.0000

TOTAL, DIRECT, AND INDIRECT EFFECTS

Part E.

Total Effect of X on Y

$\begin{array}{cccccc}\text { Effect } & \mathrm{SE} & \mathrm{t} & \mathrm{p} & \text { LLCI } & \text { ULCI } \\ 0.28 & 0.05 & 5.53 & 0.0000 & 0.18 & 0.37\end{array}$




\section{Continued}

\begin{tabular}{|c|c|c|c|c|c|c|}
\hline \multicolumn{7}{|c|}{ Direct Effect of $\mathrm{X}$ on $\mathrm{Y}$} \\
\hline & Effect & SE & $\mathrm{t}$ & $\mathrm{p}$ & LLCI & ULCI \\
\hline & 0.20 & 0.05 & 4.06 & 0.0001 & 0.10 & 0.30 \\
\hline \multicolumn{7}{|c|}{ Indirect Effect of $\mathrm{X}$ on $\mathrm{Y}$} \\
\hline & Effect & Boot SE & \multicolumn{2}{|c|}{ Boot LLCI } & \multicolumn{2}{|r|}{ Boot ULCI } \\
\hline CLT & 0.07 & 0.03 & \multicolumn{2}{|c|}{0.03} & \multicolumn{2}{|r|}{0.13} \\
\hline \multicolumn{7}{|c|}{ Normal Theory Tests for Indirect Effect } \\
\hline & Effect & se & $\mathrm{Z}$ & $\mathrm{p}$ & & \\
\hline & 0.07 & 0.02 & 3.29 & 0.0010 & & \\
\hline \multicolumn{7}{|c|}{ ANALYSIS NOTES AND WARNINGS } \\
\hline \multicolumn{7}{|c|}{ Part F. } \\
\hline \multicolumn{7}{|c|}{ Bootstrap Samples: 5000} \\
\hline \multicolumn{7}{|c|}{ Level of Confidence: 95.00} \\
\hline \multicolumn{7}{|c|}{------ END MATRIX ----- } \\
\hline
\end{tabular}

Table 5. PROCESS procedure for SPSS release 2.12.1.

Effect of MEOC on CTY via CLT

Part A. Model = 4; Y = CTY; X = MEOC; M = CLT; Statistical Controls: CONTROL = PDM; Sample size: 206

Part B. Outcome: CLT Model Summary

$\begin{array}{ccccccc}\text { R } & \text { R-sq } & \text { MSE } & \text { F } & \text { Df1 } & \text { Df2 } & \text { P } \\ 0.66 & 0.43 & 0.09 & 76.37 & 2.0000 & 203.0000 & 0.0000\end{array}$

Model

$\begin{array}{ccccccc} & \text { Coeff } & \mathrm{SE} & \mathrm{t} & \mathrm{p} & \text { LLCI } & \text { ULCI } \\ \text { Constant } & 1.56 & 0.19 & 8.23 & 0.0000 & 1.19 & 1.94 \\ \text { PDM } & 0.21 & 0.4 & 4.63 & 0.0000 & 0.12 & 0.29 \\ \text { MEOC } & 0.42 & 0.05 & 8.57 & 0.0000 & 0.32 & 0.52\end{array}$

Part C. Outcome: CTY Model Summary

$\mathrm{R}$

0.65

R-sq

0.43

Df1

Df2

$\mathrm{P}$

0.10

50.24

3.0000

202.0000

0.0000

Model

\begin{tabular}{ccccccc} 
& Coeff & $\mathrm{SE}$ & $\mathrm{t}$ & $\mathrm{p}$ & LLCI & ULCI \\
Constant & 0.92 & 0.23 & 3.94 & 0.0001 & 0.46 & 1.39 \\
CLT & 0.36 & 0.08 & 4.78 & 0.0000 & 0.21 & 0.51 \\
PDM & 0.20 & 0.05 & 4.06 & 0.0001 & 0.10 & 0.30 \\
MEOC & 0.19 & 0.06 & 3.08 & 0.0024 & 0.07 & 0.31 \\
\hline
\end{tabular}




\title{
Continued
}

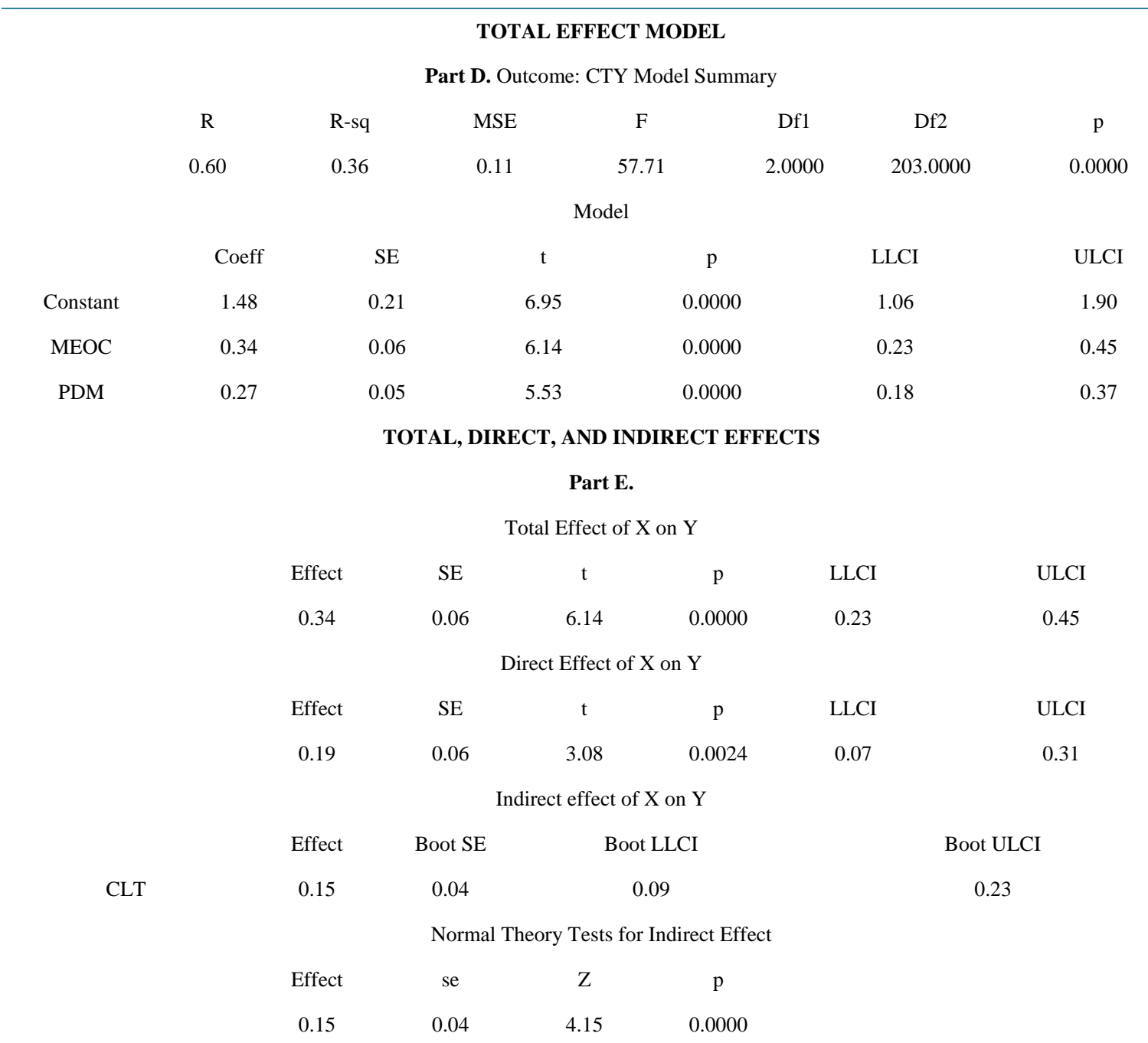

ANALYSIS NOTES AND WARNINGS

Part F.

\author{
Bootstrap samples: 5000 \\ Level of confidence: 95.00 \\ ------ END MATRIX -----
}

Part C in Table 4 and Table 5 shows the joint impact of independent variables (PDM and MEOC) and mediator variable (CLT) on dependent variable (CTY). After introducing mediator variable (CLT) in the model, $\operatorname{PDM}(\beta=0.20, \mathrm{p}<0.001, \mathrm{CI}[0.10,0.30])$ and MEOC $(\beta=0.19, \mathrm{p}<0.01$, CI [0.07, 0.31]) still significantly predicts employees creativity (CTY). Mediator variable CLT $(\beta=0.36, \mathrm{p}<0.001, \mathrm{CI}[0.21,0.51])$ was also significantly predicts dependent variable (CTY). Together these variables are explaining $43 \%\left(R^{2}=0.43\right)$ variation in the dependent variable employee's creativity (CTY) and model is significant $(\mathrm{p}<.0001)$.

Effects of CLT, PDM and MEOC are path b and path c1' and c2' respectively in Figure 2. According to Baron and Kenny [22] if after controlling for mediator variable in mediation model, independent variable still significantly predicting outcome variable, then we have partial mediation. Hence here we have evidence of partial mediation because their method has been criticized by researchers for example Preacher and Hayes [49], so in addition to Baron and Kenny’s [22] conditions Process procedure conduct bootstrap confidence intervals and 
Normal theory test.

Part D shows the effect of independent variables PDM and MEOC on employee's creativity (CTY) and model summary. PDM $(\beta=0.27, \mathrm{p}<0.001$, CI [0.18, 0.37]) and MEOC $(\beta=0.34, \mathrm{p}<0.001, \mathrm{CI}[0.23,0.45])$ significantly and positively predicts CTY. Both independent variables are explaining $36 \%\left(\mathrm{R}^{2}=0.36\right)$ variation in CTY. This means if employees participate in decision making and their manager also encourages them to behave creatively their creativity will increase. The effect of PDM on CTY is path c1 and effect of MEOC on CTY is path c2 in Figure 2.

Part E in Table 4 shows the total, direct and indirect effect of independent variable (PDM) on dependent variable (CTY) through CLT while statistically suppressing the effect of MEOC. First the total effect of X variable $\operatorname{PDM}(\beta=0.27, \mathrm{p}<0.001$, CI [0.18, 0.37]) on Y variable (CTY) is printed. This is the same as Part D of the output and path $\mathrm{c} 1$ in Figure 2. Second direct effect of X variable PDM $(\beta=.20, \mathrm{p}<0.001, \mathrm{CI}[0.10,0.30])$ on Y variable (CTY) is printed. This is the path $\mathrm{c1}^{\prime}$ ' in Figure 2. This is also the same as PDM's effect on CTY mentioned in Part $\mathrm{C}$ of the Table 4. Third indirect effect of X variable PDM $(\beta=0.07$, CI $[0.11,0.25])$ on dependent variable CTY through mediator variable CLT is reported. Indirect effect of PDM on CTY falls in CI range and zero is not present in the range this confirms mediation. This is equal to coefficient of path $\mathrm{a} 1 * \mathrm{~b}(0.21$ $\times 0.36=.07)$ and $c 1-c 1$ ' $(0.27-0.20=0.07)$ from Figure 2 . Total and direct effect of $X$ variable on $Y$ variable are significant and indirect effect of PDM on CTY is within CI range which does not include zero in it, this means indirect effect of PDM on CTY is significantly different from zero. The total, direct and indirect effects of $\mathrm{X}$ on $\mathrm{Y}$ are followed by Normal theory tests (Also known as Sobel Test) for indirect effect which is significant $(\beta=0.07, \mathrm{p}<0.01)$, this concludes that indirect effect of independent variable PDM on dependent variable CTY through mediator variable CLT is present, significant and partial.

Part E in Table 5 shows the total, direct and indirect effect of independent variable (MEOC) on dependent variable (CTY) through CLT while statistically suppressing the effect of PDM. First the total effect of X variable MEOC $(\beta=0.34, \mathrm{p}<0.001$, CI $[0.23,0.45)$ on Y variable (CTY) is printed. This is the same as Part D of the output and path $\mathrm{c} 2$ in Figure 2. Second direct effect of $\mathrm{X}$ variable MEOC $(\beta=0.19, \mathrm{p}<0.01, \mathrm{CI}[0.07,0.31])$ on Y variable (CTY) is printed. This is the path c2' in Figure 2. This is also the same as MEOC's effect on CTY mentioned in Part $\mathrm{C}$ of the Table 5. Third indirect effect of X variable MEOC $(\beta=0.15$, CI [0.09, 0.23$])$ on dependent variable CTY through mediator variable CLT is reported. Indirect effect of MEOC on CTY falls in CI range and zero is not present in the range this confirms mediation. This is equal to coefficient of path a2*b $(0.42$ $\times 0.36=0.15)$ and $c 2-c 2$ ' $(0.34-0.19=0.15)$ from Figure 2 . Total and direct effect of $X$ variable on Y variable are significant and indirect effect of PDM on CTY is within CI range which does not include zero in it, this means indirect effect of PDM on CTY is significantly different from zero. The total, direct and indirect effects of $\mathrm{X}$ on $\mathrm{Y}$ are followed by Normal theory tests (Also known as Sobel Test) for indirect effect which is significant $(\beta=0.15, \mathrm{p}<0.001)$, this concludes that indirect effect of independent variable MEOC on dependent variable CTY through mediator variable CLT is present, significant and partial.

By combining the results from Part E of Table 4 and Table 5, climate for creativity and change was found to partially mediate between independent variables (PDM and MEOC) and dependent variable CTY. So hypothesis 2 is accepted.

\section{Discussion}

Another objective of this study was examining the impact of PDM and MEOC on CTY. Consistent with PDM and MEOC literature clear support for these relationships was found and both PDM and MEOC were found to be correlated and significantly explained variation in CTY. It was argued that employee's participation in decision making will effect employee's creativity as participative decision making affects the performance, organization commitment, turnover, motivation and satisfaction of the employees, productivity [12] [13] [17]-[20] [25] and performance, organization commitment, turnover and satisfaction of the employees has significant relationship with creativity [14] [15] [21] [23]. A significant and positive relationship was found between PDM and CTY. As employees are allowed to participate in decision making, their creativity increases as well. MEOC was also found as a significant predictor of CTY which was in line with the widely stretched role of the leadership (manager, supervisor) in literature considering its effect on creativity. Leader support is positively and significantly related with subordinate's creativity [7]. Supervisory encouragement is a managerial practice that affects creativity [29]. A study by Zhang and Bartrol [34] found that leader's encouragement of creativity moderated 
the relationship between psychological empowerment and creative process engagement which influenced employee's creativity. PDM alone was explaining 24.39\% variation in CTY and MEOC alone predicted 26.65\% variation in CTY. Together PDM and MEOC explained $36.25 \%$ variation in CTY.

This study also suggested climate for creativity and change as a possible mediator between independent variables (PDM and MEOC) and dependent variable (CTY). Overall results of the analysis showed that climate for creativity and change acted as a partial mediator between independent variables (employee's participation in decision making and manager's encouragement of creativity) and dependent variable (employee's creativity). Mediation by CLT was tested between individual independent variable and dependent variable as well as between all the independent variables and dependent variable. First the mediating role of climate for creativity and change was analyzed between employee's participation in decision making and employee's creativity. The indirect effect of PDM $(\beta=0.17$, CI $[0.11,0.25])$ was significant via CLT on CTY. Also results showed that after introducing mediator (CLT) in the model $\operatorname{PDM}(\beta=0.23$, $\mathrm{p}<0.001$, CI $[0.13,0.33])$ still predicted CTY significantly. So partial mediation was found between PDM and CTY by CLT. This is also consistent with literature e.g., creative climate was found to mediate the relation of HPWS (involvement was one of the practices) and performance (innovation was one of the performance measures) [27]. Creativity is influenced by social influences [4] [38]. By participating in decision making employees can gain access to resources required to complete a project. Employees may be able to set working conditions, set standards and influence rewards system if they are involved in decision making [50]. Hence the PDM was suggested to have some of the influence transferred to employee's creativity through climate which is proven here. Second the mediating role of climate for creativity and change was analyzed manager's encouragement of creativity and employee's creativity. The indirect effect of MEOC ( $\beta=0.23$, CI $[0.15,0.32])$ was significant via CLT on CTY. Also results showed that after introducing mediator (CLT) in the model MEOC $(\beta=.23, \mathrm{p}<0.001$, CI $[0.11,0.35])$ still predicted CTY significantly. So partial mediation was found between MEOC and CTY by CLT. This is also in line with the literature. Organizational climate is proved to act as an intervening variable between leadership behavior and innovation [25]. Also leadership has not been studied as an important influence on creativity, despite its effect on work environment and the effect of work environment on creativity [7]. So the mediating role of CLT was proposed between MEOC and CTY which was again proven. Finally the mediating role of climate for creativity and change was analyzed between both independent variables (employee's participation in decision making and manager's encouragement of creativity) simultaneously and employee's creativity. The indirect effect of PDM $(\beta=0.07$, CI $[0.03,0.13])$ and MEOC $(\beta=0.15$, CI $[0.09,0.23])$ was significant via CLT on CTY when modeled together. Also both PDM $(\beta=0.20, \mathrm{p}<0.01$, CI $[0.10,0.30])$ and MEOC $(\beta=0.19, \mathrm{p}<0.001$, CI [0.07, $0.31]$ ) ware significantly and positively predicting CTY. The overall mediation model provided evidence of partial mediation by climate for creativity and change between independent variables (Employee's Participation in Decision Making and Manager's Encouragement of Creativity) and dependent variable (Employee's Creativity).

\section{Conclusions}

It was proposed that PDM and MEOC are the positive predictors of employee's creativity which was proven with the results of this study. Also we proposed climate for creativity and change as a possible mediator among PDM, MEOC and CTY which was also supported by the results of this study. Both PDM $(\beta=0.27, \mathrm{p}<0.001$, CI $[0.18,0.37])$ and MEOC $(\beta=0.34, \mathrm{p}<0.001$, CI $[0.23,0.45])$ are the positive predictors of CTY. CLT also acts as a partial mediator between independent and dependent variables. The indirect effect of PDM on CTY through CLT was $(\beta=0.07$, CI $[0.11,0.25])$. Normal theory tests for indirect effect was also significant $(\beta=$ $0.07, \mathrm{p}<0.01$ ), this concluded that indirect effect of independent variable PDM on dependent variable CTY through mediator variable CLT was present, significant and partial. Indirect effect of variable MEOC $(\beta=.15$, CI $[0.09,0.23])$ on dependent variable CTY through mediator variable CLT was present and significant. Normal theory tests also confirmed the significant $(\beta=0.15, \mathrm{p}<0.001)$ indirect effect, this concluded that indirect effect of independent variable MEOC on dependent variable CTY through mediator variable CLT was present, significant and partial.

Both participation in decision making and manager's encouragement of creativity increase employee's creativity. If the organization values creativity, then these practices should be applied. Climate for creativity and change is also found to mediate the effect of both PDM and MEOC on CTY. If PDM and MEOC are accompanied by a climate that enhances their effect, the creativity will increase as suggested by results of this study. 


\section{Limitations of the Study}

The research was carried out in restricted geographical region with limited time frame and few firms working in FMCG, Telecommunication, Textile and Banking sector. Sample size is not large enough so the findings may not be generalized to all these sectors. To generalize the results of this study analysis of a large sample may be required. Because the data was collected from employees and managers through questionnaire, some cognitive bias or social desirability bias may be present that lead to these findings. This study includes PDM and MEOC as predictors of CLT and CTY, while there are many other variables like freedom, resources availability, rewards, communication and criticism that are related with work environment (Climate) and creativity not included in the model which may be better predictors of CLT and CTY.

\section{References}

[1] Oldham, G.R. and Cummings, A. (1996) Employee Creativity: Personal and Contextual Factors at Work. The Academy of Management Journal, 39, 607-634.

[2] MacKinnon, D.W. (1965) Personality and the Realization of Creative Potential. American Psychologist, 20, $273-281$. http://dx.doi.org/10.1037/h0022403

[3] Cummings, L. (1965) Organizational Climates for Creativity. The Academy of Management Journal, 9, 220-227.

[4] Woodman, R.W., Sawyer, J.E. and Griffin, R.W. (1993) Toward a Theory of Organizational Creativity. The Academy of Management Review, 18, 293-321.

[5] Amabile, T.M., Contti, R., Coon, H., Lazenby, J. and Herron, M. (1996) Assessing the Work Environment for Creativity. The Academy of Management Journal, 39, 1154-1184.

[6] Mostafa, M. (2005) Factors Affecting Organizational Creativity and Innovativeness in Egyptian Business Organizations: An Empirical Investigation. Journal of Management Development, 24, 7-33. http://dx.doi.org/10.1108/02621710510572326

[7] Amabile, T.M., Schatzela, E.A., Monetaa, G.B. and Kramer, S.J. (2004) Leader Behaviors and the Work Environment for Creativity: Perceived Leader Support. The Leadership Quarterly, 15, 5-32. http://dx.doi.org/10.1016/j.leaqua.2003.12.003

[8] Shalley, C.E. and Gilson, L.L. (2004) What Leaders Need to know: A Review of Social and Contextual Factors That Can Foster or Hinder Creativity. The Leadership Quarterly, 15, 33-53. http://dx.doi.org/10.1016/j.leaqua.2003.12.004

[9] Alutto, J. and Belasco, J. (1972) A Typology for Participation in Organizational Decision-Making. Administrative Science Quarterly, 17, 117-125. http://dx.doi.org/10.2307/2392100

[10] Miller, K.I. and Monge, P.R. (1986) Participation, Satisfaction, and Productivity: A Meta-Analytic Review. The Academy of Management Journal, 29, 727-753.

[11] Ruh, R.A., White, J.K. and Wood, R.R. (1975) Job Involvement Values, Personal Background, Participation in Decision Making and Job Attitudes. Academy of Management Journal, 2, 300-312

[12] Muindi, F.K. (2011) The Relationship between Participation in Decision Making and Job Satisfaction among Academic Staff in the School of Business, University of Nairobi. Journal of Human Resources Management Research, Article ID: 246460.

[13] Agwu, M.O. and Olele, H.E. (2014) Perception Survey of Employees Participation in Decision Making and Organizational Productivity in Julius Berger Nigeria PLC Bonny Island. British Journal of Economics, Management \& Trade, 4, 620-637.

[14] Bhuiyan, Md.A.H. (2010) Employee Participation in Decision Making in RMG Sector of Bangladesh: Correlation with Motivation and Performance. Journal of Business and Technology (Dhaka), 5, 122-132.

[15] Hou, Y.B., Gao, G., Wang, F., Li, T.R. and Yu, Z.L. (2011) Organizational Commitment and Creativity: The Influence of Thinking Styles. Annals of Economics and Finance, 12, 411-431.

[16] Wagner III, J.A. (1994) Participation's Effects on Performance and Satisfaction: A Reconsideration of Research Evidence. Academy of Management Review, 19, 312-330.

[17] Lam, S.S.K., Chen, X.-P. and Schaubroeck, J. (2002) Participative Decision Making and Employee Performance in Different Cultures: The Moderating Effects of Allocentrism/Idiocentrism and Efficacy. Academy of Management Journal, 45, 905-914.

[18] Moorhead, G. and Griffin, R. (2004) Organisational Behaviour: Managing People and Organisations. 7th Edition, Houghton Mifflin Company, Boston.

[19] Luthans, F. (2005) Organisational Behavior. 10th Edition, McGraw-Hill Irwin, New Yolk. 
[20] Kuye, O. and Abdul-Hameed, A.S. (2011) Employee Involvement in Decision Making and Firms Performance in the Manufacturing Sector in Nigeria. Serbian Journal of Management, 6, 1-15.

[21] Cekmecelioglu, G.H. (2006) Effects of Job Satisfaction and Organizational Commitment on Creativity. İktisat İsletme ve Finans, 21, 120-131.

[22] Baron, R.M. and Kenny, D.A. (1986) The Moderator-Mediator Variable Distinction in Social Psychological Research: Conceptual, Strategic, and Statistical Considerations. Journal of Personality and Social Psychology, 51, 1173-1182.

[23] Samaneh Naddaf, B. and Ahmad, A. (2014) The Effect of Job Satisfaction on Organizational Creativity: A Case of Dey Insurance Company. International Journal of Research in Organizational Behavior and Human Resource Management, 2, 26-37.

[24] West, M.A. (1990) The Social Psychology of Innovation in Groups. In: West, M.A. and Farr, J.L., Eds., Innovation and Creativity at Work: Psychological and Organizational Strategies, Wiley, Chichester, 4-36.

[25] Isaksen II, S. and Akkermans, H.J. (2011) Creative Climate: A leadership Lever for Innovation. The Journal of Creative Behavior, 45, 161-187.

[26] Amabile, T.M. (1983) The Social Psychology of Creativity: A Componential Conceptualization. Journal of Personality and Social Psychology, 45, 357-376. http://dx.doi.org/10.1037/0022-3514.45.2.357

[27] Heffernan, M., Harney, B., Cafferkey, K. and Dundon, T. (2009) Exploring the Relationship between HRM, Creativity Climate and Organisational Performance: Evidence from Ireland. Academy of Management Conference, Chicago, 7-11 August 2009, 1-35.

[28] Sacramento, C.A. and West, M.A. (2006) Flourishing in Teams: Developing Creativity and Innovation. In: Henry, J., Ed., Creative Management and Development, Sage, London, 25-44.

[29] Amabile, T.M. (2006) How to Kill Creativity. In: Henry, J., Ed., Creative Management and Development, Sage, London, 18-24.

[30] Anderson, N.R. and West, M.A. (1996) The Team Climate Inventory: The Development of the TCI and Its Applications in Teambuilding for Innovativeness. European Journal of Work and Organizational Psychology, 5, 53-66. http://dx.doi.org/10.1080/13594329608414840

[31] Amabile, T.M. (1996) Creativity and Innovation in Organizations. Harvard Business School Background Note 396-239, January 1996.

[32] Isaksen, S.G., Lauer, K.J., Ekvall, G. and Britz, A. (2001) Perceptions of the Best and Worst Climates for Creativity: Preliminary Validation Evidence for the Situational Outlook Questionnaire. Creativity Research Journal, 13, 171-184. http://dx.doi.org/10.1207/S15326934CRJ1302_5

[33] Christensen, B.T. and Jønsson, T. (2011) Why Do Participation in Decision Making Enhance Creativity in Work Groups?-An Integrative Review. Creative Encounters.

[34] Zhang, X.M. and Bartol, K.M. (2010) Linking Empowering Leadership and Employee Creativity: The Influence of Psychological Empowerment, Intrinsic Motivation, and Creative Process Engagement. Academy of Management Journal, 53, 107-128. http://dx.doi.org/10.5465/AMJ.2010.48037118

[35] Zhou, J. and George, J.M. (2003) Awakening Employee Creativity: The Role of Leader Emotional Intelligence. The Leadership Quarterly, 14, 545-568. http://dx.doi.org/10.1016/S1048-9843(03)00051-1

[36] Smith, M., Busi, M., Ball, P. and van der Meer, R. (2008) Factors Influencing an Organization's Ability to Manage Innovation: A Structured Literature Review and Conceptual Model. International Journal of Innovation Management, 12, 655-676.

[37] Ahmadi, A.A. and Emamipour, Z. (2013) A Study on Relationship between Organizational Climate and Creativity. Management Science Letters, 3, 2709-2716.

[38] Amabile, T.M. (2013) Componential Theory of Creativity. In: Kessler, E.H., Ed., Encyclopedia of Management Theory, Sage Publications, London, 134-139. http://dx.doi.org/10.4135/9781452276090.n42

[39] Gong, Y.P., Kim, T.-Y., Lee, D.-R. and Zhu, J. (2013) A Multilevel Model of Team Goal Orientation, Information Exchange and Creativity. Academy of Management Journal, 56, 827-851. http://dx.doi.org/10.5465/amj.2011.0177

[40] Mitchell, T.R. (1973) Motivation and Participation: An Integration. Academy of Management Journal, 16, 670-679. http://dx.doi.org/10.2307/254699

[41] Ekvall, G. and Ryhammar, L. (1999) The Creative Climate: Its Determinants and Effects at a Swedish University. Creativity Research Journal, 12, 303-310. http://dx.doi.org/10.1207/s15326934crj1204_8

[42] Gelade, G.A. and Ivery, M. (2003) The Impact of Human Resource Management and Work Climate on Organizational Performance. Personnel Psychology, 56, 383-404. http://dx.doi.org/10.1111/j.1744-6570.2003.tb00155.x

[43] Isaksen, S.G. and Lauer, K.J. (2002) The Climate for Creativity and Change in Teams. Creativity and Innovation 
Management, 11, 74-86.

[44] Zhou, J. and George, J.M. (2001) When Job Dissatisfaction Leads to Creativity: Encouraging the Expression of Voice. Academy of Management Journal, 44, 682-696. http://dx.doi.org/10.2307/3069410

[45] Hayes, A.F. (2013) Introduction to Mediation, Moderation, and Conditional Process Analysis: A Regression-Based Approach (Methodology in the Social Sciences). The Guilford Press, New York.

[46] Preacher, K.J. and Kelley, K. (2011) Effect Size Measures for Mediation Models: Quantitative Strategies for Communicating Indirect Effects. Psychological Methods, 16, 93-115. http://dx.doi.org/10.1037/a0022658

[47] Field, A. (2013) Discovering Statistics Using IBM SPSS Statistics. Sage Publications, London, 418.

[48] Smart, J.C. and Tierney, W.G., Eds., (2002) Higher Education: Handbook of Theory and Research, Volume 17. Spring, Berlin.

[49] Preacher, K.J. and Hayes, A.F. (2004) SPSS and SAS Procedures for Estimating Indirect Effects in Simple Mediation Models. Behavior Research Methods, Instruments, \& Computers, 36, 717-731. http://dx.doi.org/10.3758/BF03206553

[50] Thibaut, J. and Walker, L. (1975) Procedural Justice: A Psychological Analysis. Lawrence Erlbaum Associates, Hillsdale. 